\title{
University Lecturers and Students Preparedness for Online Teaching and Learning in Zimbabwe
}

\author{
Prof. Stella Muchemwa, PhD \\ Midlands State University (MSU), Zimbabwe \\ Corresponding Mail: muchemwas@staff.msu.ac.zw
}

\begin{abstract}
The outbreak of COVID 19, which disrupted the normal lecture delivery system in universities, profoundly impacted Zimbabwe as a nation. This study investigated on university lecturers and students' preparedness to online teaching and learning at the outbreak of COVID 19 in the country. The study also looked at how these two groups adjusted and what still need to be done to effect e-learning. The researcher carried out massive interviews to both lecturers and students. The study employed the thematic data processing approach. Findings showed that university lecturers and students were caught unaware and unprepared for alternative learning modes though they did their best to rise above the challenges. Lecturers from very few well-to-do universities got either or both data bundles and gadgets. Universities experienced the following challenges: limited accessibility to internet, limited mobile networks, unreliable electricity supply, lack of appropriate technological gadgets, lack of technical know-how, high levels of stress and low performance level for both lecturers and students. The study concluded that the e-learning that was introduced as a mitigating measure, left a lot to be desired and this needs to be 'fixed' in preparation for future similar calamities and general technological advancement. The study recommended national and university funding of necessary electronic gadgets, e-learning infrastructure and data bundles for smooth running of e-learning programs.
\end{abstract}

Keywords: Zimbabwe; COVID 19; e-learning; public state universities; private universities

\section{Introduction}

Universities play a pivotal role in a country as 'knowledge generators' for they provide the skills that underpin the national development (Bekoe, 2020). These institutions have well organized systems which all along seemed to be systematically programmed until when the outbreak of COVID 19 disrupted their order of operation worldwide. The pandemic called for human creativity. Therefore, swift, sound and proper decisions in universities became a necessity. New EdTech Classroom (2019) argued that in order to achieve novel solutions, what need to be done first is to identify challenges, assess options and then implement solutions in dynamic environments. A uniform pattern of reactions happened world-wide, that is closure of institutions, sending students home and resorting to delivering of instruction remotely where it was possible while accepting a lost academic period where remote delivery was impossible (Bassett \& Arnhold, 2020).
It should be well noted that almost all the students in the universities were affected by the outbreak of COVID 19; a pandemic which Pokhrel and Chhetri (2021) said has created the largest disruption of education systems in human history, affecting nearly 1.6 billion learners in more than 200 countries. However, the impact of the closure of universities affected countries differently mainly due to disparities in economic developments among these countries.

In nearly all countries, universities resorted to technologically assisted distance learning as a way of mitigating learning time loss. Some countries found it easier to implement than others. Developed countries like Spain simply and easily asked their instructors to prepare online content and offer online classes; China as well, with similar robust connectivity, successfully offered distance learning UNESCO (2020). Contrary, the developing world, 
with limited accessibility to internet and relevant technological gadgets, have challenges in reaching out their students (Murgatrotd, 2020).

Africa, in general, faced challenges in carrying out the technologically remote learning. Pokhrel and Chhetri (2021) report said that in Sub-Saharan Africa, $89 \%$ of leaners have no access to home computers; $82 \%$ have no internet access while around 56 million learners live in places with acute limited mobile networks. Bassett and Arnhold (2020) put internet penetration level in Africa at as low as $39.3 \%$.

In Kenya, Areba (2020) defined the categories of those parents who suffered most during the COVID 19 period, trying to supplement their children's education; the poor, the vulnerable and the marginalised parents who normally earn their living through informal employment and businesses. Such parents failed to access the necessary technological gadgets such as smart phones, computers radios and televisions, among others. Such failure to source these materials, as Pokhrel and Chhetri (2021) put it across, widened the gap of inequality in the education sector in Kenya. The Zimbabwean situation neatly fits in the Kenyan situation discussed by Araba.

In Zimbabwe, there are nineteen universities; thirteen of them are public state universities while six are non-state (private) universities. They are all under the supervision of Zimbabwe Council for Higher Education (ZIMCHE) which monitors quality in institutions of higher education. All these universities were affected by the outbreak of COVID 19 in variegated ways. Bassett and Arnhold (2020) argued that in adopting online teaching at tertiary level, there was an expectation which assumed and required a level of technical capacity, hardware and infrastructure, which is not the reality for students around. The study was guided by the following research questions

1. What were the lecturers and students' online teaching/learning experiences during the COVID 19 pandemic in Zimbabwe?

2. How prepared were lecturers and students to the introduced online teaching/learning and which challenges did they encounter?

3. Which adjustments still need to be made in order to make online university teaching and learning viable in the Zimbabwean context?

\section{Review of Related Literature}

This section presents the review of related literature and studies:

\section{Experiences during COVID 19 Pandemic}

A plethora of studies on COVID 19 were carried out in 2020 especially on its impact on education. The outbreak of the pandemic affected the whole globe and those in the education sector have to quickly and carefully react to the situation. Kecojevic, Basch, Sullivan and Davi (2020) argued that the COVID-19 pandemic era has been a period of upheaval for college students. In their study, they assessed the factors associated with the increased levels of mental health burden among 162 undergraduate college students in Northern New Jersey, the region of the U.S. that was severely impacted by the outbreak of COVID-19. The study collected data on different areas including behaviour changes, academic and everyday difficulties as well as mental health measurements (depression, anxiety, somatization, and stress) from the participants. Findings showed students' academic difficulties and high levels of mental health distress. High levels of depression were associated with difficulties in focusing on academic work under the prevailing COVID 19 conditions. More females than males were stressed and were unable to focus on academic work to the extent of obtaining medications. The study concluded that the COVID19 pandemic made a significant negative impact on mental health of college students. A related study was carried out in India by Ahlawat (2020), examining the effect of COVID-19 on the students and the education system. Results showed a decrease in students 'understanding due to associated problems the students met in e-learning. They therefore preferred the normal face-to-face learning from their lecturers.

Sangster, Stoner and Flood (2020) made a worldwide study of 45 countries on the impact of COVID 19 on university education. They found that the biggest problem that was reported by both faculty and students was on high level of stress experienced. Also, it was impossible to offer high quality academic services when lecturers were working beyond manageable levels in an alien environment to which they were not accustomed to.

Countries were affected differently; Bekoe (2020) argued that in Africa, most institutions of higher learning hurriedly responded to an extraordinary 
event which compounded their already existing challenges of budgetary inadequacies, systemic inefficiencies, low adoption of technology and low capacity for generating funds internally. He noted that universities were unprepared to deliver online teaching. Bekoe (2020) witnessed some of the lecturers moonlighting and being overburdened by academic work especially those not well versed in the technology.

A study in Africa by Muftahu (2020) focused on the implications of COVID-19 pandemic on higher education; he identified matters arising and the challenges of sustaining academic programs with specific attention to developing universities in the African context. Findings of the study indicated that COVID-19 pandemic has pushed universities in different nations beyond their limits toward developing appropriate and creative alternatives. These alternatives included: resorting to e-learning, equipping academic staff with online instruction skills and electronic gadgets operation as well as encouraging students to complete their education requirements through online learning.

\section{Experiences and Challenges in Zimbabwe}

Moyo-Nyede and Ndoma (2020) argued that in its response strategy to closure of schools due to COVID 19, the Ministry of Education in Zimbabwe focused on remote-learning services via radio programming, digital/online resources and the distribution of supplementary learning materials as indicated in Zimbabwe Education Cluster, 2020. The two also highlighted that Afrobarometer survey data from 2017 and 2018 show that a majority of Zimbabweans do not have mobile phones with internet access, computers and reliable electricity supply while only one in three regularly went online, a situation that makes e-learning a great challenge. General observation also showed that a great number of university students in the country remained inaccessible to remote learning while lecturers had no prepared learning materials to send to students, let alone the know-how to engage in elearning.

There is however hope in Zimbabwe as Bekoe (2020) argued that the situation is not hopeless since there are some success stories that can be showcased for others to learn from including those of the Zimbabwe Open University that has been channelling graduates for several decades.

\section{Mitigation Measures}

Bekoe (2020) observed that in this technological age, universities of the future will be ones that transcend borders and more precisely, virtual ones without physical classrooms. He also argued that universities of the future will make use of artificial intelligence for interactivity and content delivery. This means that there is need for preparation and appropriate mitigation measures. Areba, (2020) in a study proposed the following measures to address education digital challenges: utilization of ICTs to reach-out the students and to stimulate alternate modes of delivery (satellite, computers, radio, television and mobile phones as well as having discussions with the service providers of data bundles for cheap rates to education institutions. UNESCO (2020) offered tips for providing remote learning: assessment of IT possibilities; exploring various options for distance learning; prioritization of difficulty subjects and examination classes; training teachers on e-learning strategies; creating support communities among teachers and students for cross-referencing information and, above all, considering students with disabilities in all planning. This study sought to find out lecturers and students' preparedness to online teaching and learning in Zimbabwe which was necessitated by the COVID 19 outbreak. The study also focussed on how these two groups adjusted to the situation at hand and what still need to be done in order to make online university teaching and learning viable in the Zimbabwean context.

\section{Research Methodology}

The researcher gathered information from university lecturers and students in Zimbabwe, a country with thirteen state public and six private universities. The researcher conducted semistructured interviews to ten lecturers ( 6 state and 4 private) and ten students ( 6 state and 4 private) mainly using WhatsApp, e-mails and telephone calls as well as face-to-face interview where the situation permitted. WhatsApp university groups and general observations also contributed to the data accessibility.

The researcher analysed data through descriptive analysis: a technique in which data is summarized and interpreted according to previously determined themes and where direct quotations are frequently used to reflect the opinions of the interviewed individuals in a striking way, (Yıldııım \& Şimşek, 
quoted in Berkant, Derer \& Derer, 2020). This study adhered to research ethics as there was voluntary and informed consent on the part of the participants. The researcher observed participants' right to anonymity and privacy. Again, the information gathered was presented unaltered.

\section{Results and Discussion}

Findings are presented according to three research question that guided the study.

Research question one: What were the lecturers and students' online teaching/learning experiences during the COVID 19 pandemic in Zimbabwe?

In Zimbabwe, as was observed world-wide by Bassett and Arnhold (2020), universities were closed and students were sent home in March 2020. The university authorities initially thought that the pandemic was short lived; they only tried to do something when the universities had taken long in closure. Thus, what Muftahu (2020) observed, that for students to complete their education requirements, online learning became imperative, was also true for the Zimbabwean situation.

Students' experiences varied greatly depending on the type of university they were attending. In general, public state universities faced more challenges than the private ones.

Public state universities resorted mainly to WhatsApp and e-mails for learning communications. A number of students concurred that lecturers taught via WhatsApp and used the same platform to send study materials while the e-mail was used as complementary channel for sending notes and general communications.

Some lecturers also confirmed the use of WhatsApp, which, when compared to alternatives such as online classrooms, turned to be much better. Although some lecturers said that WhatsApp teaching worked well, many students found it problematic. The usual way of WhatsApp communication was by means of recorded voicenotes. However, students had concerns. One student who said that her lecturers were giving them notes via e-mail and explained them on WhatsApp complained:

The voice-notes were usually too long (about three minutes each) in sets of ten. This means thirty minutes per communication by one lecturer. Yet, upon opening my WhatsApp, I could find two or three lectures' information. It was quite exhausting and difficulty to concentrate on. Sometimes the information was not clear for it was based on the assumption that we had read the given notes when, in fact, we had not. Personally, I could not read all the throngs of notes as well as listening to all these voice-notes. I could struggle to reach the $6^{\text {th }}$ voice note. It was stressful (Excerpt 1).

This finding concurs with Kecojevic, Basch, Sullivan and Davi (2020) whose research findings revealed stress among college students and declared the COVID-19 pandemic era as a period of upheaval for students.

A student from another university also said that her lecturers used WhatsApp lectures with the same troublesome result. She bemoaned its impact saying:

In Mathematics courses, a lecturer may send us a picture of a mathematical problem and asks us to work on it. In response, we also send our answers in the same manner. If there is a correct answer among students' posts, the lecturer just indicates the correct one. If not, the lecturer posts the correct answer without giving any explanation. We hardly comprehend anything in this manner (Excerpt 2).

She went on lamenting: Excerpt 3: "Even when we have questions, which we always have, we cannot ask them."

When the researcher asked her why they could not ask the lecturer questions, she exposed another problem associated with handling WhatsApp ethics by the students: "We misused our WhatsApp portal and we are now restricted. Only the group admin can post information"(Excerpt 4). Similar findings on students' limited comprehension of online information were exposed by Ahlawat (2020) whose study showed a decrease in students 'understanding due to associated problems the students met in elearning.

On the issue of online classroom, although universities had the online classroom facility, it was underutilized. One student said: "We have an elearning portal, only one lecturer out of seven (1/7) uses it just to post study material and assignments. Zoom classroom learning could not take off" (Excerpt 5). 
One lecturer, who seems to represent a number of lecturers from public state universities explained why it was so:

\begin{abstract}
My account of my experiences is pretty much of a personal experience but probably can also be true for other lecturers especially at my university. Due to the outbreak of COVID 19 in Zimbabwe in 2020, we faced many challenges in terms of lesson delivery and communication with students. Change was inevitable. Initially we decided to use the google classroom which we thought would work miracles in solving our lecturing challenges but later discovered that it was very expensive and out of reach especially when considering our economic stature in the country, which is on the lower side. This affected mainly our students and even some of the lecturers. Some lecturers had no proper functioning gadgets, lacked technical operational skills and had no data to engage in Google classroom operation. We could not therefore use the google classroom (Excerpt 6).
\end{abstract}

A number of public universities therefore took up WhatsApp teaching (complemented by e-mailing communications) as their first move despite the challenges that have been alluded above. Many more challenges were encountered as shown in one of the students' experiences:

I was fortunate to have connectivity and data bundles all the time. I could feel for my peers who were in the rural areas. Most often than not, they asked me to open their emails so that I could inform them of what was taking place. Sometimes my friends even asked me to open their final results (despite how much people treat final exams with confidentiality). I updated them of the lecturers' communication on WhatsApp. Some of them had no enough bundles to download attachments and I had to do that for them. I had to call them in the event of an important notice (Excerpt 7).

When giving a general comment on the 2020 elearning experiences, although they seemed to understand their predicament, most of the students preferred face-to-face learning as compared to online learning. This finding is the same as that for Ahlawat (2020). They said that it was difficulty for them to comprehend tasks when not seeing a lecturer. One student boldly added: "In other words, under our circumstances, learning is greatly compromised by online approach" (Excerpt 8).

The adversities experienced by lecturers and students at public state universities were very different from those private universities. All lectures were online and were usually successful mainly because lecturers received new laptops, data bundled as well as online lecturer seminar series. One of the students from such a university said that the online experience was an opportunity to learn more, with limited challenges. Another one from a similar university happily narrated: "We use the Google class portal to attend lectures. Notes and relevant videos are also provided. These lectures are recorded and we can visit them whenever necessary especially when revising for examinations" (Excerpt 9).

On responding to the question of data bundles, the feedback was: "Yes, data is expensive but my friends and I manage economically. Network is sometimes a problem but we can manage to attend our google classes "(Excerpt 10).

From the same source, I gathered that Google classroom attendance was fairly high; usually with only 3 or 4 (in a class of about 30) failing to attend, an indicator that the students afforded the data bundles needed for Google classroom attendance.

The respondent continued: "My University is an expensive one. Most of the students are from affluent families who can afford both school fees and other school necessities. Those who struggle economically usually go to state universities" (Excerpt 11).

One responded cheerfully explained:

Even our final exams were online. They were well tailor-made for the situation. Personally, I had no challenges and I got similar grades to what I used to get during normal semesters. However, online learning is not challenge free as it might appear even when all necessities seem to be available (Excerpt 12).

One student exposed one of the challenges that are difficult to detect and prevent: "At times we just log-into the portal for the lecturers to see us and disappear, do other things and not concentrating at all. The plural "we" referred to the respondent and classmates" (Excerpt 13). 
While university students had a challenging time in learning due to COVID 19 induced learning changes, first year students had a nasty experience. This was aggravated by many factors including lack of university life experience, no university orientation, among others.

One respondent, who insisted to use the plural "we" saying that his experiences were similar to those of his colleagues, sadly said; "Our university experience as Freshmen is a difficulty one. We lack motivation and are totally confused. It is difficult to communicate with our lecturers. We don't even know how to approach them; not knowing their expectations" (Excerpt 14).

Another challenge for these freshmen was on lack of technical skills for online activities such as online tests and assignments. The same informant said: "I used to attach assignments instead of uploading them to the portal. They could not be sent therefore. I spent hours on that. I later learnt the right thing from my friends after a long struggle" (Excerpt 15). He went on to say: "Portal notes can only be read online and cannot be downloaded for future use (or it is my ignorance on these issues). It becomes very expensive to be online always when one wants to read the notes" (Excerpt 16).

Despite the online learning challenges, some informants echoed that online learning seemed to be the only practicable solution considering their situation. They could site some of their positive aspects e-learning experiences. They said that online learning activates independency and selfrelevancy; learning from home is a good thing without hassles of accommodation and food which is rampant in today's universities; there are social benefits of being with the family while learning and multiple activities can be done while learning.

Some lecturers could also site some benefits of online teaching. One lecturer said: "Working from home is convenient and flexible; moonlighting is a possibility. Again, there are no fuel costs for some of us who used to drive to a neighboring town to teach" (Excerpt 17).

Other benefits include reduction of overcrowding on campus especially for state universities with large numbers of students. These large crowds can also be taught online without space limitations. When considering marking, lecturers echoed that, assignments can be marked online reducing vulnerability to contracting COVID 19. Again, lecturers are provided opportunities for innovation in the new mode of lesson delivery for the system exposes existing educational technology gaps in the universities ready for improvements. Other lecturers noted that the online system, once established, becomes a time saver, for instance, online materials can be used over and over again. Above all, if online learning is done well, it can revolutionize teaching and learning for the better. One can therefore say that the outbreak of COVID 19 has given universities a new experience and a platform to improve their teaching technologies.

Research question two: How prepared were lecturers and students to the introduced online teaching/learning and which challenges did they encounter?

Universities in Zimbabwe were caught unaware by the pandemic. They were therefore unprepared but they did their best to rise above the floods of challenges before them by offering alternative teaching strategies. They however encountered several challenges on the part of both lecturers and students.

On the part of the students, they encountered many distractors at home which prevented them from concentrated on their school work; these include household chores. While student from well-to-do universities had light problem, for instance, of missing school and friends, most student, especially from public state universities had real issues. As supported by one lecturer, elearning costs and poor connectivity seem to be the major hindrances:
Even the seemed-to-be cheapest mode of lesson delivery are expensive to some of our students. ...Some students are still out of reach, in areas with no internet connectivity. Lack of electricity in most of the rural areas where some students live compounded with numerous power-cuts, especially during the rain-season, greatly hindered the e-learning activities (Excerpt 18).

Another lecturer used strong terms to describe the costs saying: "Data costs are very prohibitive" (Excerpt 19).

To worsen the already existing problems of poor internet connectivity and unavailability in some 
areas, online classroom platforms consume a lot of data bundles (characteristics of web-based platforms) and need good network.

Other common challenges for both lecturers and students include lack of requisite e-learning gadgets that are compatible to online learning; old, cheap and low-quality assets (phones and laptops) which are incompatible with online learning. Also, some students pay school fees late and therefore join online classes late into the semester while other students fail to register and cannot access online platforms causing further complication in the education system. Some informants even questioned the quality and security issues for online assessment. Moyo-Nyede and Ndoma (2020) found related results that the majority of Zimbabweans do not have mobile phones with Internet access as well as computers and reliable electricity supply, a situation that makes e-learning a great challenge.

Even in universities that managed to embrace online teaching, there were other challenges. One lecturer said: "It has been difficult to implement online examinations particularly in engineering and technology programmes and courses" (Excerpt 20).

There was also an issue of adjusting to the new way of teaching as most programmes have been designed for face-to-face teaching and readjusting has been a problem for both students and lecturers. This further negatively affected both. One lecturer has said that Online teaching has forced some lecturing personnel to quit the profession for they failed to match with the technological demanded skills. Sangster, Stoner and Flood (2020) made similar observations when lecturers in their study could not offer high quality academic services for they worked beyond manageable levels in an alien environment to which they were not accustomed to.

Holding all other factors constant, lecturers, like their students counterpart, preferred face-to-face teaching to online teaching.

The face-to face interim within the total lock down periods made our work easier for we could even explain our e-learning model to the students. Although it was a staggered program meeting few groups at a time, it helped us a lot (Excerpt 21).

Another lecturer said:
At my university, we are not given data bundles, neither do we receive any type of online assistance. We cannot therefore engage on any form of online learning. We just capitalized on the two weeks face-toface interim teaching. Otherwise, the students would have not written their final examinations (Excerpt 22).

While all these changes were taking place, the universities were busy trying to adjust and to find what worked. Therefore, they needed time to communicate their positions to the students. This in turn confused and stressed the students and even the lecturers. One student complained that at one time, he heard of the postponement of the interim face-to-face lectures when he was halfway on his journey to school. He further moaned:

Communication was very bad from the registrar's office on school issues. There were short notices on everything even on issues that really matter; we were told of the commencement of final examinations in a shocking manner, 'you will start next week', just like that (Excerpt 23).

In trying to find out if the lecturers could not assist with information, he answered: Lecturers could not help us with much, 'Ask the responsible authorities'; 'I don't know'; 'I will confirm with authorities and come back to you,' and other such unclear retorts is what we got from them (Excerpt 24).

One can say that both the universities (lecturers included) and the students were not prepared for the Online teaching/learning that was induced by COVID 19 pandemic in Zimbabwe. The pandemic intensified in March 2020 causing a total shutdown in the country. The universities resorted and embarked to Online teaching although they faced many challenges which included lack of technological hardware and software suitable for Online teaching.

Research Question three: Which adjustments need to be made in order to make online university teaching and learning viable in the Zimbabwean context?

It is interesting to note that some students came up with valuable possible solutions to online learning problems. This comprised what the state, the responsible ministry, universities, lecturers and staff can do. They also slot themselves as capable of bringing in some solutions. 
Students made a call for the state to support universities financially as well as subsiding online learning related equipment so as to make online learning a reality. They urged the universities to be prepared in advance in case of such calamities, for example, by permanently using e-learning as supplementary to face-to-face learning even during good times so that the e-learning system is already in place. It was also recommended that the responsible ministry and the universities should make arrangements with data bundles providers, for instance, Econet, Net One and other providers in the country for relatively cheaper student packages.

To solve the problem of some local online portals that can only be accessed on campus, students proposed creation of universal portal which could be accessed from any location. They also advised on the adjustment of some rigid portal system to allow them to download notes so as to be able to read them even when offline.

First year students reminded the universities that orientation is now more of a necessity in the current situation than in the past normal university days. They reported that the current scenario is traumatic and should not let be a norm.

Some of the students' recommendations were already being employed in some universities, for instance, data bundles costs being attached to school fees so that all paid-up students can access them. Their main argument was that parents usually struggle and manage to pay fees but many of them cannot afford data bundles.

Students proposed that lecturers should consider possible students challenges when setting due dates for online assignments and tests. They reminded all lecturers to use online classroom platforms, saying that they can comprehend better when seeing a lecturer explaining. They preferred videos instead of just seeing notes on any of the possible platforms.

Students were rational in their approach for they acknowledged that they also have a part to play by being resilience to challenges; being self-motivated, having good time management skills and being cooperative especially by availing themselves online when they are needed. By doing these, they said, they support online learning very much. They also said that they could create virtual communities with the hope of giving each other support as well as creating some excitement along the education journey.
Lecturers contributed on what can be done in order to improve online teaching in Zimbabwe. The concurred that workshops for lecturers were necessary for many of them lacked online teaching and technical operational skills. They proposed for university lecturers' motivation, for instance, in the form of loans for them to purchase functional gadgets. Lecturers requested for airtime and data bundles; even those who were receiving such, argued that they were never enough when considering the google classroom demands and virtual meetings.

Some lecturers revealed that institutions were financially struggling, thus they called for the state to chip in to help its institute of higher learning by providing the critical resources so that lecturers can engage in Google classroom in terms of laptops, wifi and data bundles. Areba (2020) made similar suggestion advocating for the government to allot funds for e-learning infrastructure and gadgets.

\section{Conclusions and Recommendations}

This section presents the conclusions that emanated from the findings of the study and then comes up with recommendations.

\section{Conclusions}

The study concluded that the online experiences for both lectures and especially students varied greatly due to the nature of their university. Only few lecturers and students from the few well-to-do universities (which charge high fees, with relatively better resources and have students from affluent families) seemed to successfully handle online teaching and learning with few hustles. Otherwise, the majority of their counterparts in the state universities had challenging experiences. This is a clear indicator that both universities and students were not prepared for the outbreak of COVID 19 meaning that the e-learning that was enforced as a mitigating measure in March 2020 in Zimbabwe, left a lot to be desired. The challenges at hand need to be 'fixed' in preparation for future similar calamities and general technological advancement.

\section{Recommendations}

The study recommended national and university funding for electronic gadgets, online learning infrastructure and data bundles for smooth running of e-learning programmes. Online instructional skills and electronic gadget operation workshops should be done at university levels to abreast the lecturers for the work at hand. 


\section{References}

Ahlawat, B. (2020). Understanding the Effect of COVID-19 on the Education System and the Students in Bangalore Region of India. Asian Journal of Education and Social Studies, 12(3), 1-8. https://doi.org/10.9734/ ajess/2020/v12i330310.

Areba, G. N. (2020). "COVID-19 Pandemic Impact on Kenyan Education Sector: Learner Challenges and Mitigations." Journal of Research Innovation and Implications in Education 4(2), 128-139. From www.jriie.com.

Bassett, R. M. \& Arnhold N (2020). COVID-19's immense impact on equity in tertiary educationhttps://blogs.worldbank.org/edati on/COVID-19s-immense-impact-equitytertiary-education

Bekoe, R. (2020). COVID -19 Exposes Universities' Unpreparedness for Virtual Classrooms. https://www.modernghana.com/news/99 3518/COVID-19-exposes-universities-unp reparedness.html

Berkant, H. G.; Derer, N. B. \& Derer, O.K. (2020). The effects of different types of written corrective feedbacks. English Language

Teaching Educational Journal (2020). http://www.journal 2.uad.ac.id/ index.php /eltej/article/view/3136/pdf

Kecojevic, A.; Basch, C. H,; Sullivan, M. \& Davi, N. K. (2020). Impact of the COVID-19 epidemic on mental health of undergraduate students in New Jersey, cross-sectional study. https://doi .org/10. 137 1/journa I.pon e.0239696
Moyo-Nyede, S. \& Ndoma, S. (2020). Limited Internet access in Zimbabwe a major hurdle for remote learning during pandemic http://www.afrobarometer.org/publications /ad371-limited-internet-access-zimbabwemajor-hurdle-remote-learning-during-pan de mic.

Muftahu, M. (2020). Higher Education and COVID-19 Pandemic: Matters Arising and the Challenges of Sustaining Academic Programs in Developing African Universities. International Journal of Educational Research Review www.ijere.com

Murgatrotd, S. (2020, March). COVID-19 and Online learning, Alberta, Canada. doi:10.13140 /RG.2.2.31132.8512.

New EdTech Classroom (2019). https://tarsusdistr ibution.co.za/wp-content/ upload s/HP-SAEducation-Book-20191023.pdf.

Pokhrel, S \& Chhetri, R. (2021). A Literature Review on Impact of COVID-19 Pandemic on Teaching and Learning. Higher education for the Future, 8 (1) https://journal s.sagep ub.com/doi/full/10.1177/234763112098348 1

Sangster, A.; Stoner, G. \& Flood, B. (2020). Insights into accounting education in a COVID-19 world, AccountingEducation, 29:5, 431562, DOI: $10.1080 / 09639284.2020 .1808487$.

UNESCO (2020): Coronavirus Impacts Education https://en.unesco.org/themes/educationemergencies/coronavirus-school-closures 